\title{
Phosphodiesterases regulate BAY 41-2272-induced VASP phosphorylation in vascular smooth muscle cells
}

\section{Shaquria P. Adderley*, Chintamani N. Joshi, Danielle N. Martin and David Anthony Tulis}

Department of Physiology, Brody School of Medicine, East Carolina University, Greenville, NC, USA

Edited by:

Douglas G. Johns, Merck \& Co., USA

Reviewed by:

Christine Ivashchenko,

GlaxoSmithKline, USA

David Behm, GlaxoSmithKline, USA

Brett Mitchell, Texas A\&M Health

Science Center, USA

\section{*Correspondence:}

Shaquria P. Adderley, Department of Physiology, East Carolina University, Brody School of Medicine, 6E-71, 600 Moye Blvd., Greenville, NC 27834,

USA.

e-mail: adderleys@ecu.edu
BAY 41-2272 (BAY), a stimulator of soluble guanylyl cyclase, increases cyclic nucleotides and inhibits proliferation of vascular smooth muscle cells (VSMCs). In this study, we elucidated mechanisms of action of BAY in its regulation of vasodilator-stimulated phosphoprotein (VASP) with an emphasis on VSMC phosphodiesterases (PDEs). BAY alone increased phosphorylation of VASP Ser239 $_{\text {and }} \mathrm{VASP}_{\text {Ser157, }}$, respective indicators of PKG and PKA signaling. IBMX, a non-selective inhibitor of PDEs, had no effect on BAY-induced phos-

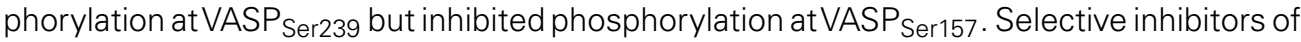
PDE3 or PDE4 attenuated BAY-mediated increases at VASP Ser239 $_{\text {and VASP }}$ Ser157, whereas PDE5 inhibition potentiated BAY-mediated increases only at VASP Ser157. In comparison, 8BrcGMP increased phosphorylation at $\mathrm{VASP}_{\text {Ser239 }}$ and $\mathrm{VASP}_{\text {Ser157 }}$ which were not affected by selective PDE inhibitors. In the presence of 8Br-cAMP, inhibition of either PDE4 or PDE5

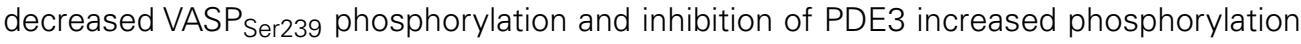

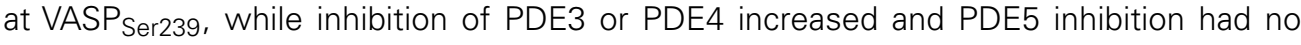
effect on VASP $\mathrm{Ser}_{157}$ phosphorylation. These findings demonstrate that BAY operates via CAMP and cGMP along with regulation by PDEs to phosphorylate VASP in VSMCs and that the mechanism of action of BAY in VSMCs is different from that of direct cyclic nucleotide analogs with respect to VASP phosphorylation and the involvement of PDEs. Given a role for VASP as a critical cytoskeletal protein, these findings provide evidence for BAY as a regulator of VSMC growth and a potential therapeutic agent against vasculoproliferative disorders.

Keywords: BAY 41-2272, cGMP, cAMP, phosphodiesterase, soluble guanylyl cyclase, VASP

\section{INTRODUCTION}

Vascular smooth muscle cell (VSMC) growth is an integral process in the pathophysiology of numerous cardiac and vascular disorders; thus, approaches aimed at minimizing abnormal VSMC growth are of significant clinical and therapeutic interest. Recent advances in therapy has aimed to reduce vessel growth through targeted gene delivery, use of drug-coated stents, and localized delivery of pharmacologic agents in the vascular wall. Cyclic guanosine monophosphate (cGMP) and cyclic adenosine monophosphate (cAMP) are second messengers involved in many cellular processes including those associated with vascular growth (Indolfi et al., 1997; Varenne et al., 1998). Cyclic nucleotide signaling is considered antiproliferative in cardiac and vascular tissues and has been the target of numerous basic science and clinical studies (Feil et al., 2005; Tulis, 2008). Both cAMP and cGMP are hydrolyzed

\footnotetext{
Abbreviations: BAY, BAY 41-2272; cAMP, cyclic adenosine monophosphate; cGMP, cyclic guanosine monophosphate; CILO, cilostazol; DMSO, dimethyl sulfoxide; ERK, extracellular-signal-regulated kinase; EPACs, exchange proteins activated by cAMP; FBS, fetal bovine serum; GTP, guanosine triphosphate; IBMX, isobutylmethylxanthine; NO, nitric oxide; PDE, phosphodiesterase; PDE3, cGMP-inhibited PDE; PDE4, cAMP-specific PDE; PDE5, GMP-specific PDE; pGC, particulate guanylate cyclase; PKA, cAMP-dependent protein kinase; PKG, cGMP-dependent protein kinase; ROL, rolipram; sGC, soluble guanylate cyclase; VSMC, vascular smooth muscle cell; VAR, vardenafil; VASP, vasodilator-stimulated phosphoprotein; ZAP, zaprinast.
}

by phosphodiesterases (PDEs) which catalyze hydrolysis to the $5^{\prime}$ monophosphate in order to maintain steady state levels of cyclic nucleotides (Bender and Beavo, 2006).

Phosphodiesterases represent a target for many current pharmacotherapies and as such have major clinical appeal. The major PDEs present in VSMCs are the CGMP-inhibited PDE (PDE3), the cAMP-specific PDE (PDE4), and the major cGMP-hydrolyzing enzyme PDE5 (Polson and Strada, 1996; Rose et al., 1997; Tilley and Maurice, 2002; Aizawa et al., 2003; Rybalkin et al., 2003; Kass et al., 2007a,b). Balloon angioplasty increases the expression and activity of PDE3 and PDE4 in VSMCs (Zhao et al., 2008). Both PDE3 and PDE4 contribute to the regulation of VSMC proliferation and in fact, cilostazol, a PDE3 inhibitor, has shown promise in clinical trials for treatment of restenosis (Douglas et al., 2005). Likewise, PDE5 and its inhibitors have gained considerable attention because of the role that they play in the vasculature. For example, PDE5 inhibitors such as Viagra and Revatio are currently in use for treatment of erectile dysfunction and pulmonary hypertension, respectively (Boolell et al., 1996; Hemnes and Champion, 2006), clearly showing clinical importance of PDEs.

The nitric oxide (NO)-sGC-cGMP signaling pathway is of major importance in the cardiovascular system where it regulates normal functions such as VSMC relaxation and growth (Ignarro et al., 1986; Lucas et al., 2000). Cardiovascular diseases are often attributed to insufficiency in $\mathrm{NO}$ production due to 
endothelial dysfunction and associated attenuation of NO-sGCcGMP signaling (Challah et al., 1997; Freedman et al., 1998; Cai and Harrison, 2000; Loscalzo, 2001). The molecular mechanisms of cGMP signaling are not well understood and studies suggest that NO can both promote and inhibit pathological vascular remodeling (Garg and Hassid, 1989; Rudic et al., 1998; Kawashima et al., 2001; Ozaki et al., 2002; Sasaki et al., 2008). Clinical use of the NO system is limited to indirect NO donors which suffer complications including tolerance, tachyphylaxis, and toxicity (Rindone and Sloane, 1992; Sydow et al., 2004; Munzel et al., 2005). This has led to the development of synthetic, NO-independent activators of sGC which directly stimulate the enzyme and promote cGMP signaling without the deleterious effects attributed to NO. Interestingly these agents can operate via mechanisms either dependent or independent of substrate heme (Ko et al., 1994; Stasch et al., 2001, 2002; Straub et al., 2001). BAY 41-2272 (BAY), a novel NO-independent sGC stimulator, is a parent drug of the heme-dependent class whose therapeutic potential is just beginning to be highlighted (Boerrigter and Burnett, 2007; Mendelev et al., 2009; Roger et al., 2010).

A target for cyclic nucleotides that may affect VSMC growth is vasodilator-activated serum phosphoprotein (VASP), a cytoskeletal protein which has diverse effects on cell motility, migration, and adhesion (Benz et al., 2009). VASP was originally characterized as a substrate for the cyclic nucleotide-dependent protein kinases, PKA, and PKG (Butt et al., 1994), with three distinct phosphorylation sites ( $\mathrm{Ser}_{157}, \mathrm{Ser}_{239}, \mathrm{Thr}_{278}$ ) identified (Butt et al., 1994; Haffner et al., 1995). Despite the conventional thought that phosphorylation of VASP at $\operatorname{Ser}_{239}$ and $\operatorname{Ser}_{157}$ occurs by PKG and PKA, respectively, more recent studies suggest that there is crosstalk and that all three sites can be cross-phosphorylated by PKA, PKG, PKC, and the metabolic regulator AMP kinase (Chitaley et al., 2004; Blume et al., 2007). The phosphorylation pattern of VASP is complex and dynamic, and although VASP phosphorylation continues to be used as a biochemical marker for activation of PKA and PKG, its precise cellular and molecular functions remain to be fully determined.

It was recently demonstrated that BAY increases VASP phosphorylation and attenuates vascular remodeling in the pulmonary vasculature in a hypoxia-induced rat model (Deruelle et al., 2006; Thorsen et al., 2010). In support, we recently demonstrated that BAY increases cAMP, cGMP, VASP phosphorylation and inhibits proliferation of rat A7R5 VSMCs (Mendelev et al., 2009), rat primary VSMCs, and neointimal formation in the rat carotid artery (Joshi et al., 2011). In the current study we sought to investigate the influence of PDEs on VASP phosphorylation in response to BAY using rat primary VSMCs. We hypothesized that PDEs modulate BAY-induced increases in cGMP/cAMP and phosphorylation of VASP. Results demonstrate that BAY operates in primary VSMCs via indirect crosstalk with cyclic nucleotides and through mechanisms involving selective VASP phosphorylation and PDE regulation. These functional attributes of BAY add to its characterization and understanding of the molecular basis of how BAY functions in VSMCs and add to its potential as a pharmacologic candidate for the treatment of cardiovascular disorders.

\section{MATERIALS AND METHODS RAT PRIMARY VSMC CULTURE}

Following procedures established in our laboratory (Durante et al., 1993; Liu et al., 2009; Mendelev et al., 2009), thoracic aorta VSMCs were obtained from male Sprague-Dawley rats (100-125 g) and cultured in Dulbecco's modified Eagle's medium supplemented with $10 \%$ fetal bovine serum (FBS) and Primocin $(100 \mathrm{mg} / \mathrm{L}$; Invivogen) at $37^{\circ} \mathrm{C}$ in $95 \%$ air $/ 5 \% \mathrm{CO}_{2}$. Cells were split and propagated through passage 6 . In general for each assay the " $n$ " is equal to three to five wells per treatment group done in triplicate. In each figure legend the exact total number of wells for each experiment is listed as " $n$ " (i.e., $n=15$ indicates five wells per plate with three plates total used or vice versa). All studies abided by the guidelines of the Institutional Animal Care and Use Committee and conformed to the Guide for the Care and Use of Laboratory Animals (US National Institutes of Health, Publication No. 85-23, revised 1996).

\section{CYCLIC NUCLEOTIDE ASSAYS}

The content of cGMP and cAMP was determined using two separate enzyme immunoassay kits (Sigma, St. Louis, MO, USA). In brief, VSMCs were pretreated with PDE inhibitors or vehicle dimethyl sulfoxide (DMSO) or phosphate buffered saline (PBS) for 30 min prior to stimulation with BAY $(1 \mathrm{nM}-10 \mu \mathrm{M}$, Alexis Biochemicals, Farmingdale, NY, USA) for specific times $(\leq 60 \mathrm{~min})$. Reactions were stopped with $\mathrm{HCl}$ and protein concentrations determined with a bovine serum albumin (Thermo Scientific, Waltham, MA, USA) protein assay. Inhibitors used for the cGMP/cAMP assays were: isobutylmethylxanthine (IBMX; $10 \mu \mathrm{M}$ ), a general PDE inhibitor (Calbiochem, San Diego, CA, USA), and zaprinast (ZAP; $10 \mu \mathrm{M}$; MP Biochemicals) and vardenafil (VAR; $50 \mathrm{nM}$; Toronto Research Chemicals, North York, ON, Canada), selective PDE5 inhibitors. The concentrations of inhibitors chosen were based on reported $\mathrm{IC}_{50}$ values and experiments performed in other cell types (Rose et al., 1997; Bender and Beavo, 2006; Keswani et al., 2009). In addition, inhibitors were used at concentrations that, by themselves, do not increase baseline levels of cyclic nucleotides. The vehicle for BAY, IBMX, and ZAP was DMSO and the vehicle for VAR was PBS.

\section{IN-CELL WESTERN}

Phosphorylation of VASP was examined by use of an established cell-based immunocytochemical assay for monitoring kinase signaling pathways (Chen et al., 2005). Rat VSMCs were seeded $(\sim 20,000$ cells/well) in 96 well plates and once adhered, pretreated with a PDE inhibitor or vehicle for $30 \mathrm{~min}$ after which they were stimulated with BAY for $60 \mathrm{~min}$. The inhibitors used for In-Cell Westerns were cilostazol (CILO; $10 \mu \mathrm{M})$, a selective PDE3 inhibitor (Sigma-Aldrich), rolipram (ROL; $10 \mu \mathrm{M}$ ), a selective PDE4 inhibitor (Tocris, Minneapolis, MN, USA), ZAP, VAR, and IBMX. The vehicle for CILO and ROL was DMSO. After incubations media was removed and cells were fixed with $4 \%$ formalin in PBS for $20 \mathrm{~min}$. Cells were washed and permeabilized with PBS containing $0.1 \%$ Triton X-100, followed by $1 \times$ PBS $+0.1 \%$ Tween-20. The cells were blocked with IR blocking solution (Rockland, Immunochemicals, Gilbertsville, PA, USA) for $3 \mathrm{~h}$ and then incubated with rabbit polyclonal anti-rat primary 
antibodies directed against VASP at phospho $\operatorname{Ser}_{239}$ (1:500; Cell Signaling), VASP at phospho $\operatorname{Ser}_{157}$ (1:500; Cell Signaling) or $\alpha-$ tubulin (1:500; Sigma) overnight at $4^{\circ} \mathrm{C}$. Cells were washed with PBS $+0.1 \%$ Tween-20 followed by incubation with two secondary antibodies: IRDye 800CW (1:500; Odyssey) and Alexa Fluor 680 for $1 \mathrm{~h}$. Afterward, cells were washed with PBS containing $0.1 \%$ Tween-20 followed by plain PBS. The plate was allowed to dry overnight and scanned using the appropriate channels for detection with a Li-Cor Odyssey Imager (LI-COR Odyssey; LI-COR Biosciences, Lincoln, NE, USA). The proteins were quantified by fluorescence and normalized with respect to $\alpha$-tubulin within each well.

\section{DATA ANALYSIS}

Statistical significance between experiments was defined as a $P \leq 0.05$ and was determined using an analysis of variance (ANOVA). If a significant change occurred, a multiple replicate Bonferroni or Tukey post hoc test was performed to identify individual differences. Results were reported as mean \pm SEM.

\section{RESULTS}

\section{THE EFFECT OF BAY-INDUCED INCREASES IN CYCLIC NUCLEOTIDES IN RAT PRIMARY VSMCs}

BAY 41-2272 increased the content of both cGMP and cAMP, with an increase observed for cGMP at $100 \mathrm{nM}$ after $15 \mathrm{~min}$ (Figure 1A) and for cAMP at $1 \mathrm{nM}$ after $5 \mathrm{~min}$ (Figure 1B). At $10 \mu \mathrm{M}$ BAY significantly elevated cGMP (Figure 2A) levels without marked effects on cAMP (Figure 2B) after $60 \mathrm{~min}$, yet IBMX, a nonselective PDE inhibitor, failed to significantly potentiate these effects. Interestingly, IBMX alone significantly increased cAMP content under these conditions. Therefore, given the overall goal of this study to evaluate PDE involvement in the anti-mitogenic effects of BAY previously observed at $10 \mu \mathrm{M}$ (Joshi et al., 2011), for all subsequent experiments BAY was used at $10 \mu \mathrm{M}$.

\section{THE EFFECT OF INHIBITION OF PDE5 ACTIVITY ON BAY-INDUCED INCREASES IN CYCLIC NUCLEOTIDES IN RAT PRIMARY VSMCs}

To shed light on a recent controversy about the inhibition of PDE5 activity by BAY (Mullershausen et al., 2004) and in order to determine the contribution of PDEs in regulating BAY-stimulated cyclic nucleotide signaling, rat primary VSMCs (passage $\leq 6$ ) were treated individually with one of two chemically distinct selective inhibitors of PDE5: zaprinast (ZAP), a PDE5 antagonist with moderate potency $\left(\mathrm{IC}_{50} \sim 1 \mu \mathrm{M}\right)$, (Ballard et al., 1998; Bender and Beavo, 2006; Lugnier, 2006), or vardenafil (VAR), a highly potent inhibitor of PDE5 (IC $50 \sim 1 \mathrm{nM}$ ), (Bender and Beavo, 2006), prior to stimulation with BAY. ZAP $(10 \mu \mathrm{M})$ did not have a significant effect on the levels of cGMP induced by BAY alone (Figure 3A), while VAR ( $50 \mathrm{nM}$ ) significantly potentiated the increases in cGMP induced by BAY (Figure 3B). Similarly, ZAP had no effect on BAYinduced cAMP yet VAR potentiated BAY-mediated increases in cAMP (Figure 3C). Of note, the individual effects of ZAP or VAR alone on cAMP and cGMP content were not different from that of vehicle controls (data not shown).

\section{EFFECT OF INHIBITORS OF SGC ON BAY-STIMULATED cGMP}

Based on the recent findings for BAY in terms of its mechanism of action and dependence on sGC and cGMP (Stasch et al., 2001; Bawankule et al., 2005; Teixeira et al., 2006), we sought to determine if BAY-induced increases in cGMP are via direct stimulation of sGC. Primary VSMCs were incubated with two chemically dissimilar inhibitors of sGC: NS 2028 (NS, $1 \mu \mathrm{M})$ or ODQ $(10 \mu \mathrm{M})$, prior to stimulation with BAY $(10 \mu \mathrm{M}$; Garthwaite et al., 1995; Morbidelli et al., 2010). Either agent alone had no effect on cGMP or cAMP levels compared to vehicle controls (data not shown); however, respective co-incubation of each inhibitor with BAY completely attenuated the increase in cGMP induced by BAY (Figure 4). Co-treatment of the sGC inhibitors with BAY did not affect cAMP content relative to BAY alone (data not shown).

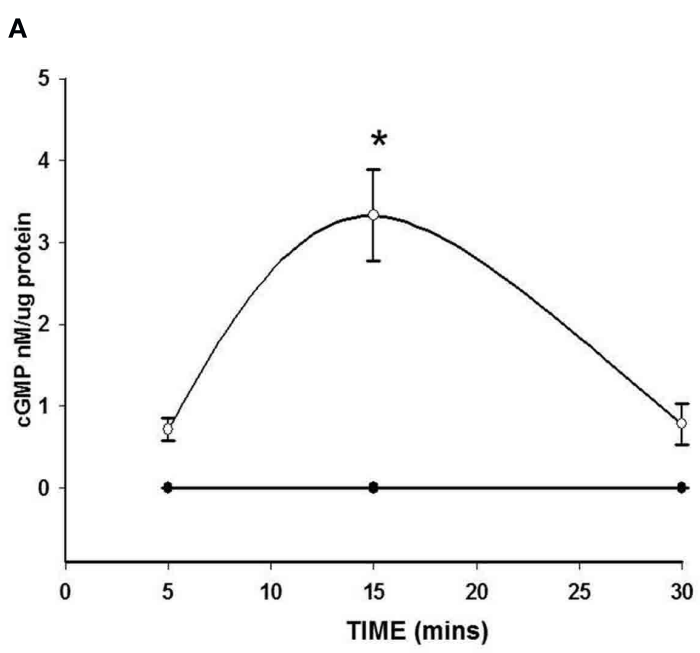

FIGURE 1 | Effect of BAY 41-2272 (BAY) on increases in cyclic nucleotides. (A) VSMCs were treated with BAY (100 nM, open circles) or vehicle (filled circles) for 5,15 , and $30 \mathrm{~min}(n=3)$. Values are the means \pm SE. ${ }^{*}$ Different

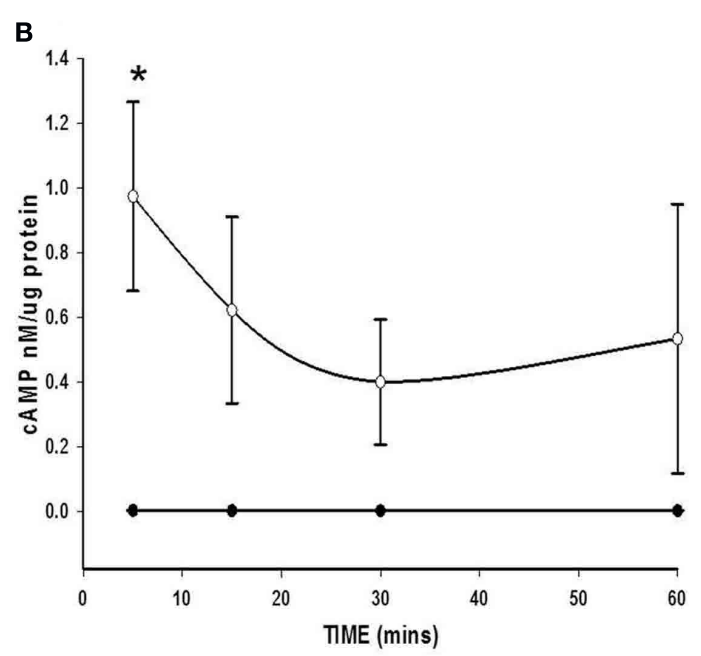

from control $(P<0.05)$. (B) VSMCs were treated with BAY $(1 \mathrm{nM}$, open circles) or vehicle (filled circles) for $5,15,30$, and $60 \mathrm{~min}(n=6)$. Values are the means $\pm S E$. ${ }^{*}$ Different from control $(P<0.05)$. 
A

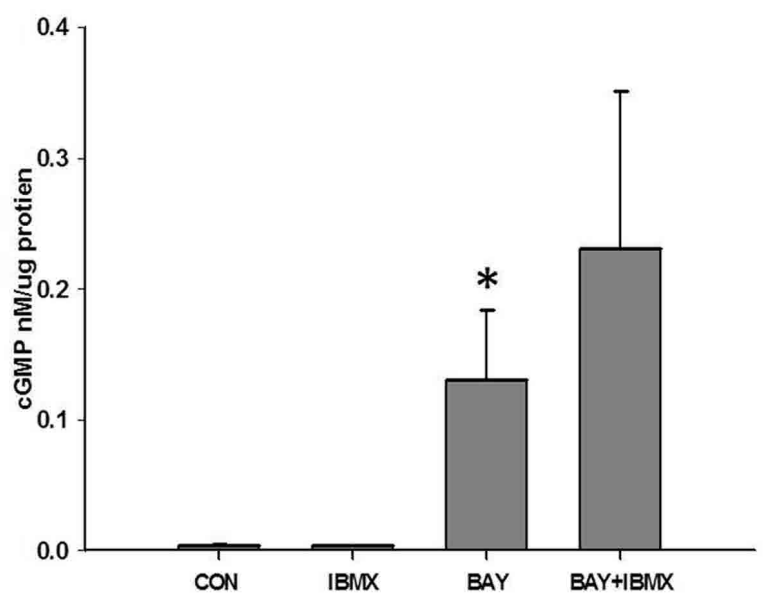

FIGURE 2 | (A) Effect of IBMX on BAY 41-2272 (BAY)-induced increases in cGMP. VSMCs were pretreated with IBMX $(10 \mu \mathrm{M})$ or vehicle for $30 \mathrm{~min}$ prior to stimulation with BAY $(10 \mu \mathrm{M})$ for $60 \mathrm{~min}(n=15)$. Values are the means \pm SE. *Different from control $(P<0.05)$. (B) Effect of IBMX on

\section{B}

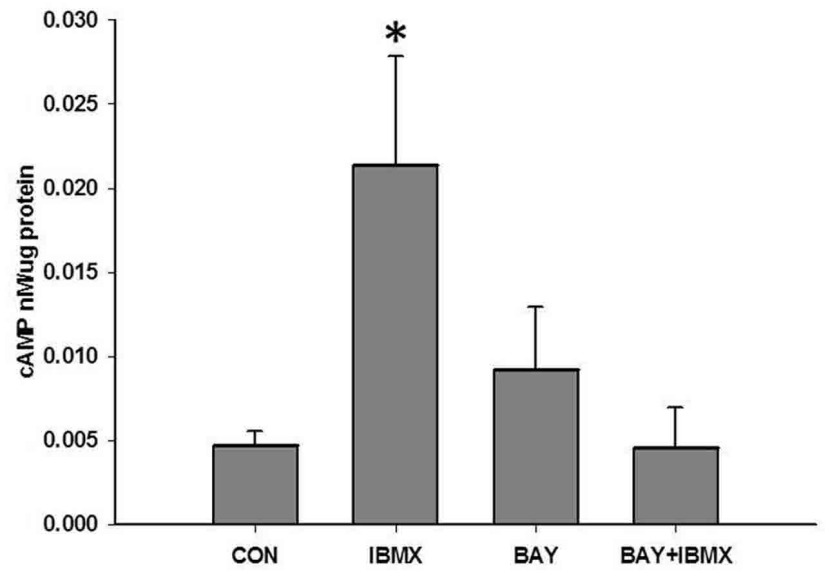

BAY-induced increases in CAMP. VSMCs were pretreated with IBMX $(10 \mu \mathrm{M})$ or vehicle for 30 min prior to stimulation with BAY $(10 \mu \mathrm{M})$ for $60 \mathrm{~min}(n=8)$. Values are the means \pm SE. ${ }^{*}$ Different from control $(P<0.01)$

\section{EFFECT OF IBMX ON BAY-INDUCED VASP PHOSPHORYLATION}

We recently reported that BAY increases phosphorylation of VASP at both Ser sites (Joshi et al., 2011). Therefore, to determine the effect of PDEs on BAY-induced differential VASP phosphorylation, primary VSMCs were stimulated with BAY $(10 \mu \mathrm{M})$ in the presence or absence of IBMX $(10 \mu \mathrm{M})$. Treatment with BAY alone significantly increased phosphorylation of both VASP Ser239 $_{2}$

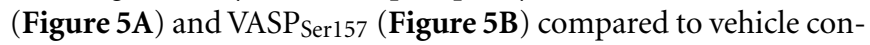
trols. Pretreatment with IBMX in the presence of BAY had no effect on $\mathrm{VASP}_{\mathrm{Ser} 239}$ (Figure 5A) but inhibited VASP $_{\text {Ser157 }}$ phosphorylation toward control levels (Figure 5B). Treatment with IBMX

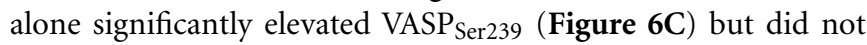

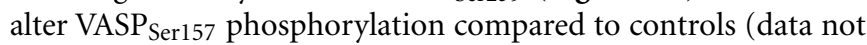
shown). Notably, none of the PDE inhibitors alone suppressed VASP phosphorylation.

\section{EFFECT OF SELECTIVE INHIBITORS OF PDES ON BAY-INDUCED VASP PHOSPHORYLATION}

In order to determine specific PDEs involved in regulation of VASP phosphorylation, primary VSMCs were incubated with selective PDE inhibitors prior to stimulation with BAY $(10 \mu \mathrm{M})$. Incubation with either the PDE3 inhibitor, cilostazol (CILO; $10 \mu \mathrm{M})$, or the PDE4 inhibitor rolipram (ROL; $10 \mu \mathrm{M}$ ) inde-

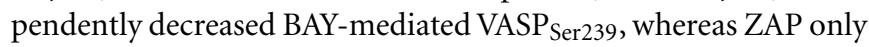
slightly (non-significantly) reduced BAY-mediated VASP Ser239 $_{2}$ (Figure 6A). In comparison, incubation with ZAP significantly potentiated while CILO and ROL inhibited VASP Ser157 $_{\text {induced }}$ by BAY (Figure 6B). Importantly, inhibition of any PDE alone (in the absence of BAY) increased VASP Ser239 $_{\text {compared to vehicle }}$

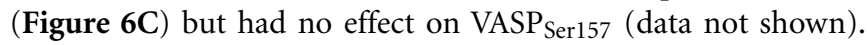
To further explore the role of PDE5 in VASP phosphorylation, primary VSMCs were incubated with the potent PDE5 inhibitor VAR $(50 \mathrm{nM})$ prior to stimulation with BAY (10 $\mu \mathrm{M})$. VAR had no

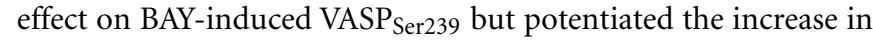
VASP $_{\text {Ser157 }}$ (Figures 7A,B, respectively).

\section{EFFECT OF INHIBITORS OF SGC ON VASP PHOSPHORYLATION}

To determine if BAY-induced phosphorylation of VASP is dependent on sGC, VSMCs were incubated with NS $2028(1 \mu \mathrm{M})$ or ODQ $(10 \mu \mathrm{M})$ prior to stimulation with BAY $(10 \mu \mathrm{M})$. Inhibition of sGC with either antagonist had no effect on BAY-mediated VASP phosphorylation at either VASP site (data not shown).

\section{EFFECT OF CYCLIC NUCLEOTIDE ANALOGS AND PDE INHIBITION ON VASP PHOSPHORYLATION}

In an effort to compare the mechanisms of BAY-induced phosphorylation of VASP to that elicited by direct cyclic nucleotide analogs, VSMCs were incubated with either 8Br-cAMP $(10 \mu \mathrm{M})$ or $8 \mathrm{Br}-\mathrm{cGMP}(10 \mu \mathrm{M})$. Compared to vehicle controls, either analog increased phosphorylation of VASP at both VASPSer $_{239}$ and VASP $_{\text {Ser157 }}$ with $8 \mathrm{Br}-\mathrm{cGMP}(10 \mu \mathrm{M})$ being more efficacious at both sites (Figures 8A,B, respectively). In order to determine if inhibition of PDE activity would affect the phosphorylation of VASP induced by these analogs, VSMCs were incubated with selective PDE inhibitors prior to addition of the analog. Incubation with ZAP, CILO, or ROL (each $10 \mu \mathrm{M}$ ) had no effect on 8Br-cGMPinduced VASP phosphorylation at either site (data not shown). In comparison, inhibition of either PDE4 or 5 decreased phosphorylation induced by $8 \mathrm{Br}$-cAMP at VASP $\mathrm{Ser}_{239}$ while inhibition of PDE3 increased the phosphorylation at VASP Ser239 $_{\text {(Figure 9A). }}$ On the contrary, ROL increased the phosphorylation induced by $8 \mathrm{Br}$-cAMP at VASP Ser157 $_{\text {while PDE5 inhibition had no effect }}$ (Figure 9B).

\section{DISCUSSION}

Cyclic AMP and cGMP are important mediators that regulate many physiological processes in cells in response to hormones and 


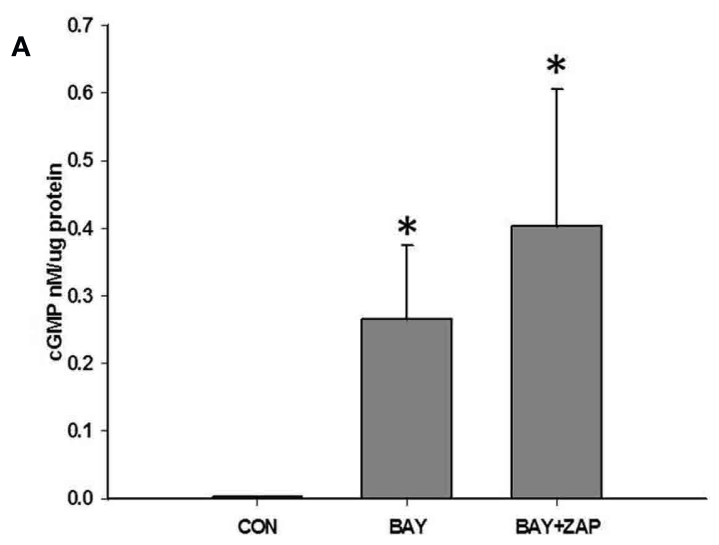

C

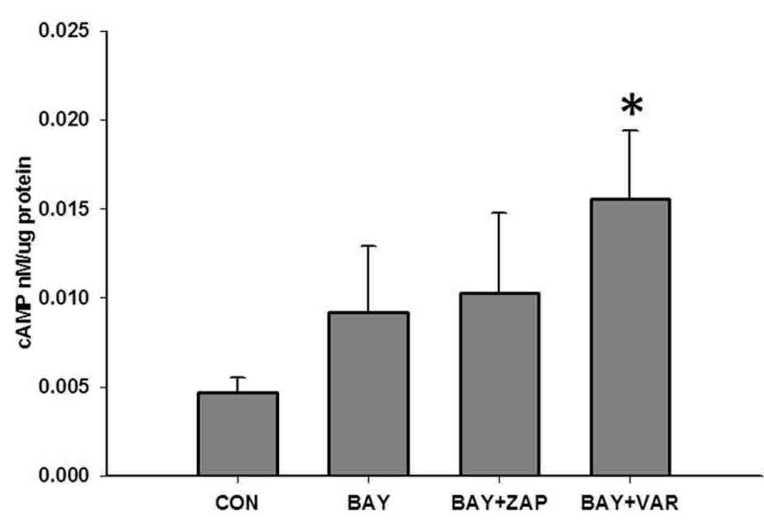

FIGURE 3 | (A) Effect of zaprinast (ZAP) on BAY 41-2272 (BAY)-induced increases in cGMP. VSMCs were pretreated with ZAP (ZAP, $10 \mu \mathrm{M})$ or vehicle for $30 \mathrm{~min}$ prior to stimulation with $\mathrm{BAY}(10 \mu \mathrm{M})$ for $60 \mathrm{~min}(n=11)$. Values are the means \pm SE. * Different from control $(P<0.05)$. (B) Effect of vardenafil (VAR) on BAY-induced increases in CGMP. VSMCs were pretreated with VAR $(50 \mathrm{nM})$ or vehicle for $30 \mathrm{~min}$ prior to stimulation with BAY $(10 \mu \mathrm{M})$ for $60 \mathrm{~min}$
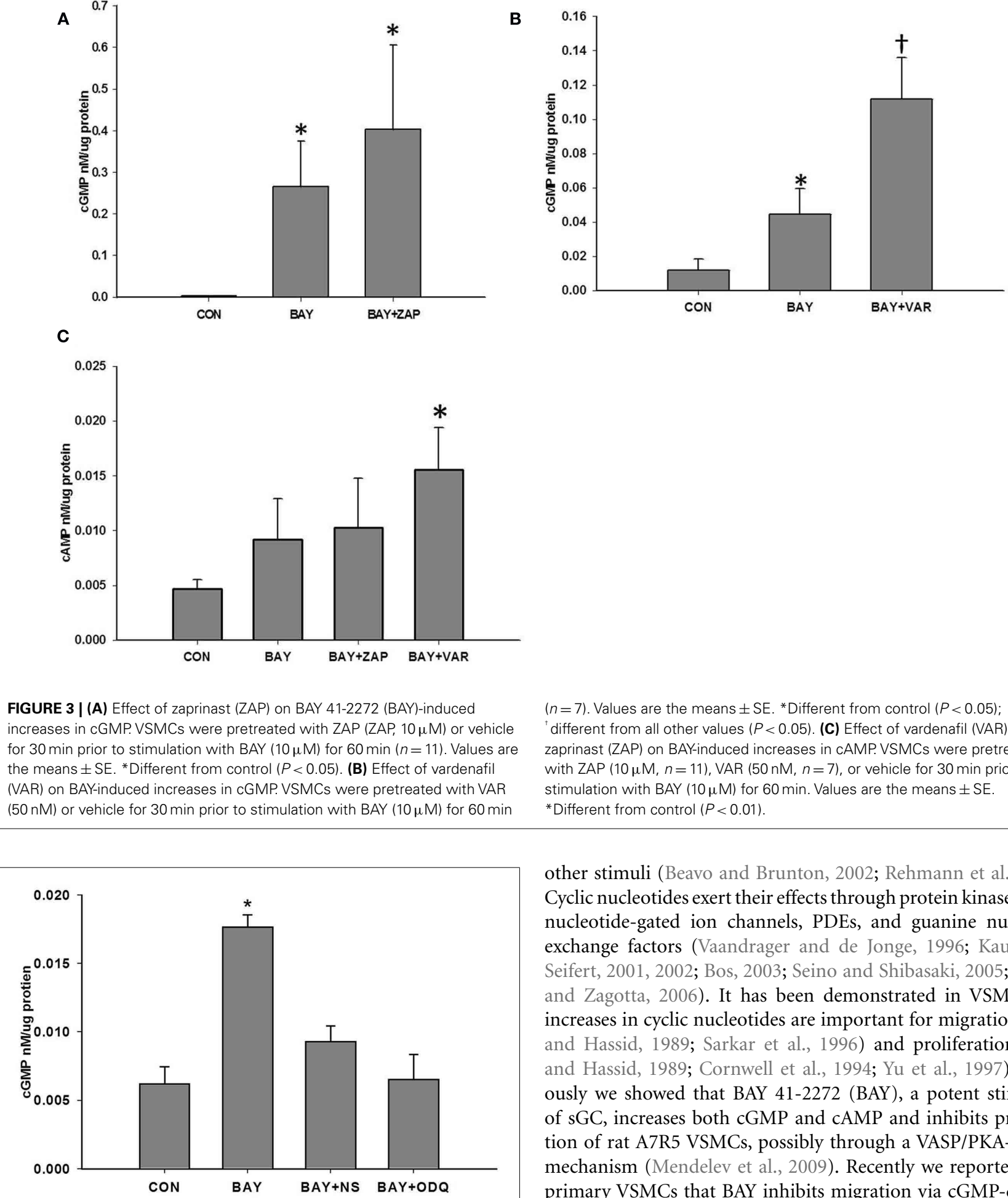

$(n=7)$. Values are the means \pm SE. ${ }^{*}$ Different from control $(P<0.05)$; ${ }^{\dagger}$ different from all other values $(P<0.05)$. (C) Effect of vardenafil (VAR) or zaprinast (ZAP) on BAY-induced increases in CAMP. VSMCs were pretreated with ZAP $(10 \mu \mathrm{M}, n=11)$, VAR $(50 \mathrm{nM}, n=7)$, or vehicle for $30 \mathrm{~min}$ prior to stimulation with BAY $(10 \mu \mathrm{M})$ for $60 \mathrm{~min}$. Values are the means $\pm \mathrm{SE}$. * Different from control $(P<0.01)$.

other stimuli (Beavo and Brunton, 2002; Rehmann et al., 2007). Cyclic nucleotides exert their effects through protein kinases, cyclic nucleotide-gated ion channels, PDEs, and guanine nucleotide exchange factors (Vaandrager and de Jonge, 1996; Kaupp and Seifert, 2001, 2002; Bos, 2003; Seino and Shibasaki, 2005; Craven and Zagotta, 2006). It has been demonstrated in VSMCs that increases in cyclic nucleotides are important for migration (Garg and Hassid, 1989; Sarkar et al., 1996) and proliferation (Garg and Hassid, 1989; Cornwell et al., 1994; Yu et al., 1997). Previously we showed that BAY 41-2272 (BAY), a potent stimulator of sGC, increases both cGMP and cAMP and inhibits proliferation of rat A7R5 VSMCs, possibly through a VASP/PKA-specific mechanism (Mendelev et al., 2009). Recently we reported in rat primary VSMCs that BAY inhibits migration via cGMP-directed

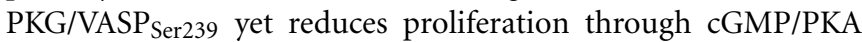
signaling (Joshi et al., 2011). In the current study we investigated the regulatory role of cyclic nucleotide-hydrolyzing PDEs on VASP phosphorylation in response to BAY in rat primary VSMCs. Results demonstrate that: (1) BAY increases content of both cAMP and cGMP; (2) BAY induces site-specific phosphorylation of VASP; 


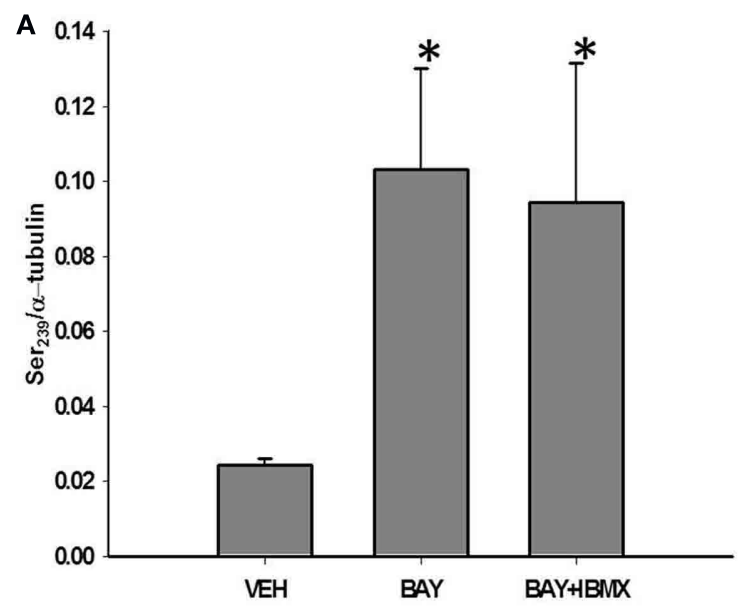

FIGURE 5 | (A) Effect of IBMX and BAY 41-2272 (BAY) on VASPSer ${ }_{239}$ phosphorylation. VSMCs were pretreated with IBMX $(10 \mu \mathrm{M})$ or vehicle control (DMSO) for 30 min prior to stimulation with BAY $(10 \mu \mathrm{M})$ for $60 \mathrm{~min}(n=5)$. Values are the means \pm SE. ${ }^{*}$ Different from vehicle control $(P<0.05)$. (B) Effect of IBMX and BAY 41-2272 (BAY) on

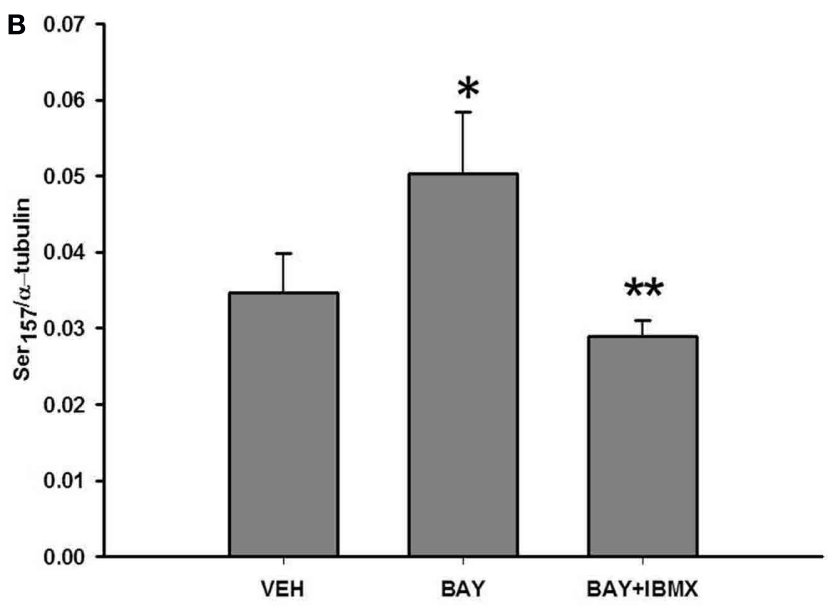

VASPSer $_{157}$ phosphorylation. VSMCs were pretreated with IBMX $(10 \mu \mathrm{M})$ or vehicle control (DMSO) for $30 \mathrm{~min}$ prior to stimulation with BAY $(10 \mu \mathrm{M})$ for $60 \mathrm{~min},(n=4)$. Values are the means \pm SE. ${ }^{*}$ Different from vehicle control $(P<0.05)$; ${ }^{*}$ different from vehicle control and BAY $(P<0.05)$.
(3) PDEs differentially regulate BAY-induced VASP phosphorylation; (4) PDE5 regulates increases in cGMP induced by BAY; and (5) the mechanisms of BAY-induced phosphorylation of VASP are unique from that of direct cGMP/cAMP analogs. These results characterize for the first time novel mechanisms of BAY in VSMCs and provide important new information on the role of PDEs and VASP in BAY-mediated growth protection.

In this study using primary VSMCs, BAY increased the levels of both CAMP and CGMP; however, because BAY increases cyclic nucleotide content at lower concentrations and different times this must be considered when using agonists of cyclic nucleotide signaling such as BAY in VSMCs. Results from PDE inhibitor studies show that PDE5 regulates BAY-induced increases in cGMP. Moreover, the increases in cAMP may be secondary to the increases in cGMP due to cGMP-mediated inhibition of PDE3 (Maurice and Haslam, 1990). These findings suggest that cyclases and PDEs present in VSMCs play critical roles in maintaining cAMP at a steady state in the presence of elevated cGMP levels. This places additional emphasis on the importance of tight regulation of cyclic nucleotides within these cells due to involvement in numerous and often redundant or reciprocal signaling pathways (Palmer and Maurice, 2000; Raymond et al., 2007; Wilson et al., 2008).

It is important to note that the intracellular concentrations of both cAMP and cGMP are never high simultaneously and that their levels are regulated both temporally and spatially (Zaccolo and Pozzan, 2002; Zaccolo and Movsesian, 2007; Nausch et al., 2008). In this study, we have seen that cAMP is tightly regulated in these cells as IBMX alone increased its levels drastically and BAY reduced these effects. Furthermore, IBMX had no effect on the increase in phosphorylation at Ser $_{239}$ but inhibited the increase in phosphorylation at $\operatorname{Ser}_{157}$, consistent with the effect of IBMX on the cyclic nucleotide content.

It is well demonstrated that an increase in cyclic nucleotides leads to phosphorylation of VASP at $\operatorname{Ser}_{157}$ and $\operatorname{Ser}_{239}$, suggesting increases in the activities of the respective kinases PKA and PKG (Butt et al., 1994; Haffner et al., 1995). Indeed, our own data as well as several recent reports (Abel et al., 1995; Chitaley et al., 2004) show cross-phosphorylation of these reported kinase-specific sites by cGMP and cAMP, suggesting promiscuity of VASP phosphorylation by otherwise distinct kinases (Chen et al., 2004). Investigation of specific PDE isoforms involved in the regulation of VASP phosphorylation induced by BAY demonstrated that inhibition of PDE3 or PDE4 reduced the increase in phosphorylation at both $\operatorname{Ser}_{239}$ and $\operatorname{Ser}_{157}$. Conversely, inhibition of PDE5 increased phosphorylation only at Ser 157 . These data suggest that BAY-induced increases in CGMP and activation of PKG occur within local intracellular pools and lend support to the argument of compartmentalization of cyclic nucleotide signaling pathways in VSMCs (Piggott et al., 2006; Nausch et al., 2008; Baillie, 2009).

Regardless of the mechanisms involved, these findings show that BAY can induce phosphorylation of both PKG and PKA sites on VASP, providing additional evidence for crosstalk between the cAMP/PKA and cGMP/PKG systems with regard to site-specific VASP phosphorylation (see Figure 10). Using chemically dissimilar inhibitors of sGC, we show that BAY operates to increase cGMP through a mechanism dependent upon sGC. However, the mechanisms for BAY-mediated increases in cAMP may be more indirect, possibly via direct inhibition of PDE5 activity (Mullershausen et al., 2004) or through increases in cGMP which then would inhibit PDE3 activity, thus increase the levels of cAMP and PKA activity (Maurice and Haslam, 1990; Degerman et al., 1997; Stasch et al., 2001). Alternatively, pharmacologic inhibition of sGC had no effect on the ability of BAY to phosphorylate VASP at either Ser $_{157}$ or Ser $_{239}$. Lack of an effect of inhibitors of sGC on VASP could be due to a non-selective, cyclase-independent effect of BAY or alternatively due to the increases in cAMP. The increases in cAMP may lead to activation of the MAPK pathway which can 

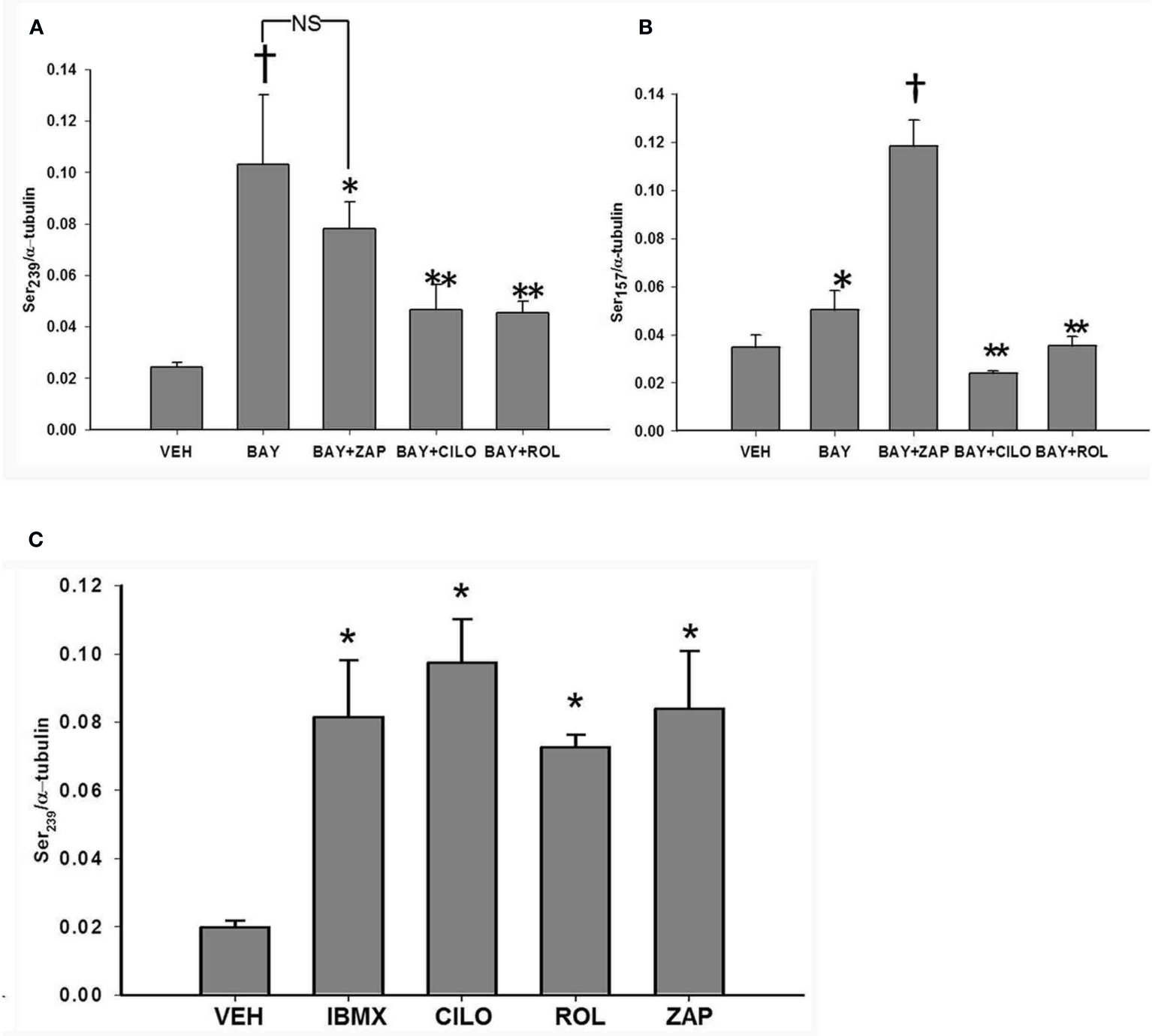

FIGURE 6 | (A) Effect of inhibitors of PDEs on VASPSer ${ }_{239}$ phosphorylation. VSMCs treated with vehicle (DMSO), cilostazol (CILO, $10 \mu \mathrm{M})$, rolipram (ROL, $10 \mu \mathrm{M})$, or zaprinast (ZAP, $10 \mu \mathrm{M})$ for $30 \mathrm{~min}$ $(n=5)$. Values are the means \pm SE. ${ }^{*}$ Different from vehicle control $(P<0.05) ;{ }^{* *}$ different from vehicle control and BAY $(P<0.05) ;{ }^{\dagger}$ different from all other values $(P<0.05)$. (B) Effect of inhibitors of PDEs on BAY 41-2272 (BAY)-induced VASPSer ${ }_{157}$ phosphorylation. VSMCs treated with BAY $(10 \mu \mathrm{M})$ in the absence or presence of cilostazol (CILO, $10 \mu \mathrm{M})$, rolipram (ROL, $10 \mu \mathrm{M})$, or zaprinast (ZAP, $10 \mu \mathrm{M}),(n=5)$. Values are the means \pm SE. * Different from vehicle control $(P<0.01){ }^{\dagger}$ different from all other values $(P<0.05)$; ** different from vehicle control and BAY $(P<0.05)$. (C) Effect of inhibitors of PDEs on BAY 41-2272 (BAY)-induced VASPSer $_{239}$ phosphorylation. VSMCs treated with BAY $(10 \mu \mathrm{M})$ in the absence or presence of cilostazol (CILO, $10 \mu \mathrm{M})$, rolipram (ROL, $10 \mu \mathrm{M})$, or zaprinast $(\mathrm{ZAP}, 10 \mu \mathrm{M})$. Values are the means $\pm \mathrm{SE} .{ }^{*}$ Different from vehicle control $(P<0.01)$. possibly lead to changes in VASP phosphorylation according to the intracellular state of the cell. One other possible explanation is that BAY activates some other unidentified kinase in this cell that can phosphorylate VASP. BAY has also been shown to have effects apart from NO such as inhibition of $\mathrm{Ca}^{2+}$ influx, stimulation of the sodium pump, or inhibition of PDE5 (Mullershausen et al., 2004; Bawankule et al., 2005; Teixeira et al., 2006). The latter is one possible explanation for this finding because an inhibition of PDE5 would increase cGMP and thus lead to phosphorylation of VASP. Thus, downstream substrate phosphorylation would not be solely based on increases in cGMP associated with sGC, demonstrating that crosstalk between the systems and phosphorylation occurs at either VASP site depending on the acute and local condition of the cells.

These conclusions are supported from experiments in which direct CAMP or cGMP analogs were added to the cells, resulting in non-selective increases in phosphorylation at both Ser $_{239}$ and Ser 157 . In these assays, 8Br-cGMP seems to be more effective at this concentration as a stimulator of phosphorylation at either site compared to 8Br-cAMP. Interestingly, in parallel studies inhibition of select PDEs did not affect phosphorylation of Ser $_{157}$ or $\mathrm{Ser}_{239}$ in the presence of $8 \mathrm{Br}-\mathrm{cGMP}$. However, in the presence of 


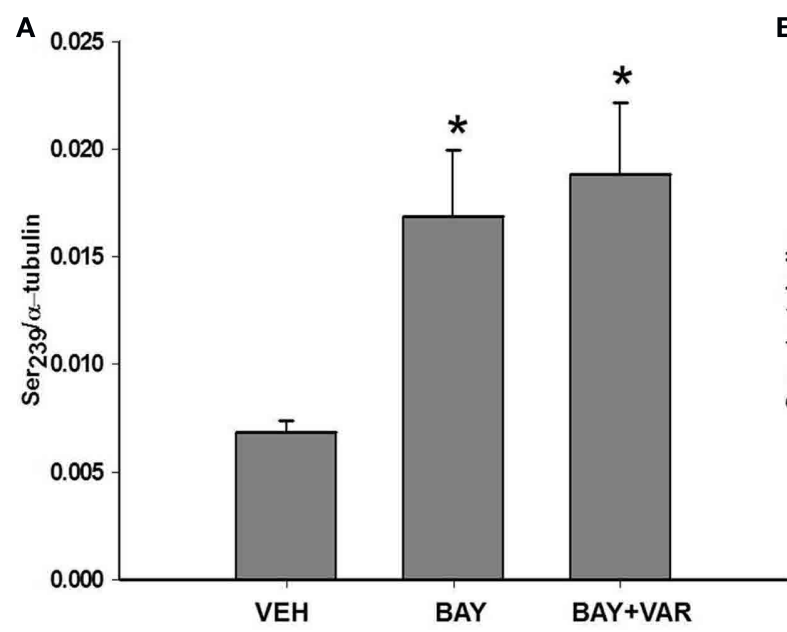

FIGURE 7 | (A) Effect of vardenafil (VAR) on BAY 41-2272 (BAY)-induced VASPSer ${ }_{239}$ phosphorylation. VSMCs were pretreated with VAR $(50 \mathrm{nM})$ or vehicle (DMSO) for 30 min prior to stimulation with $\mathrm{BAY}(10 \mu \mathrm{M})$ for $60 \mathrm{~min}(n=15)$. Values are the means $\pm \mathrm{SE}$. *Different from vehicle control $(P<0.01)$. (B) Effect of vardenafil
B

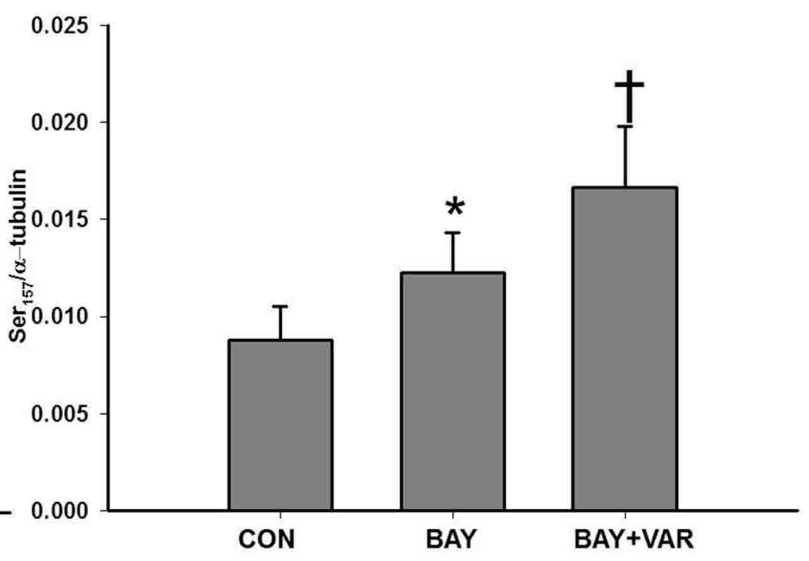

(VAR) on BAY 41-2272 (BAY)-induced VASPSer ${ }_{157}$ phosphorylation. VSMCs were pretreated with VAR $(50 \mathrm{nM})$ or vehicle (DMSO) for 30 min prior to stimulation with BAY $(10 \mu \mathrm{M})$ for $60 \mathrm{~min}(n=11)$. Values are the means \pm SE. ${ }^{*}$ Different from vehicle control $(P<0.05)$; ${ }^{\dagger}$ different from all other values $(P<0.05)$.

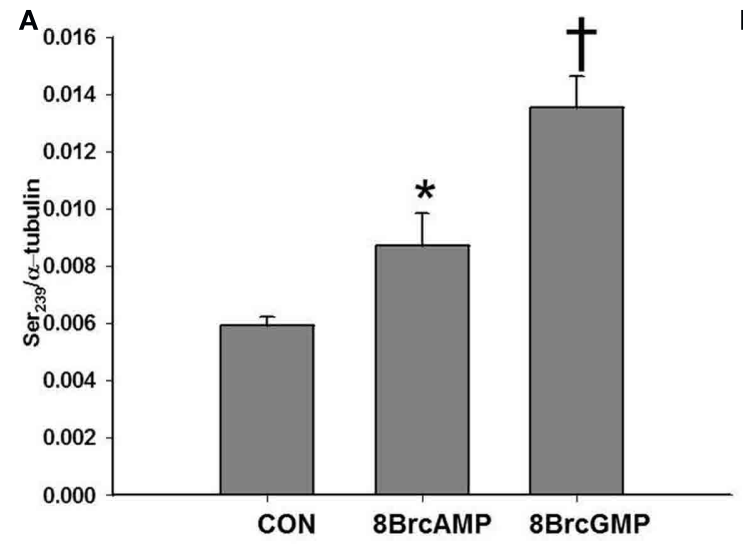

FIGURE 8 | (A) Effect of 8Br-cAMP and 8Br-cGMP on VASPSer ${ }_{239}$ phosphorylation. VSMCs were treated with 8Br-cAMP $(10 \mu \mathrm{M})$, 8Br-cGMP $(10 \mu \mathrm{M})$, or vehicle (PBS) for $30 \mathrm{~min}(n=3)$. Values are the means \pm SE. * Different from vehicle control $(P<0.05) ;{ }^{\dagger}$ different from all other values
B

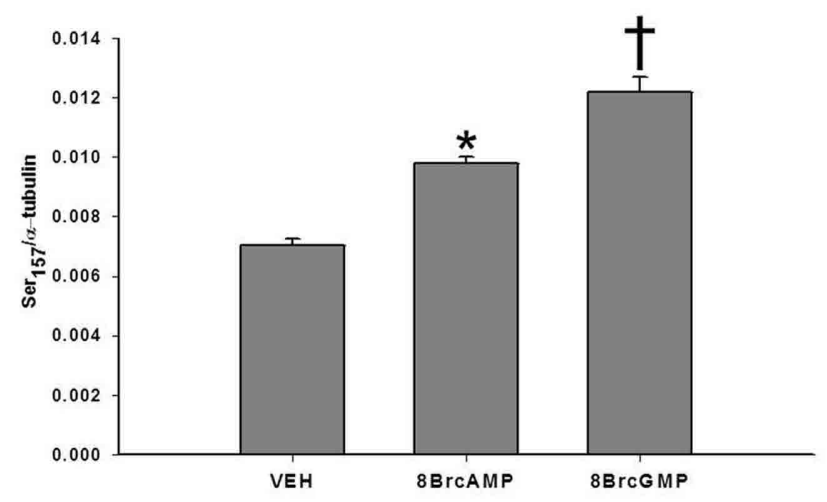

$(P<0.01)$. (B) Effect of 8Br-cAMP and 8Br-cGMP on VASPSer ${ }_{157}$ phosphorylation. VSMCs were treated with $8 \mathrm{Br}$-CAMP $(10 \mu \mathrm{M}), 8 \mathrm{Br}-\mathrm{cGMP}$ $(10 \mu \mathrm{M})$, or vehicle for $30 \mathrm{~min}(n=3)$. Values are the means $\pm S E .{ }^{*}$ Different from vehicle control $(P<0.05)$; ${ }^{\dagger}$ different from all other values $(P<0.05)$.
8Br-cAMP, inhibition of PDE3 potentiated VASP phosphorylation at both sites. It has been noted that cyclic nucleotide analogs are less efficient at inhibition or activation of PDEs themselves (Beltman et al., 1995), which could explain some of the differences in the results observed. Nonetheless, these findings confirm that the mechanism by which BAY induces phosphorylation of VASP is distinct from that of direct kinase activation via cyclic nucleotide analogs. The fact that BAY-induced increases in cAMP work by a dissimilar mechanism is further confirmed with the observed phosphorylation at $\operatorname{Ser}_{157}$, where inhibition of PDE4 potentiates and inhibition of PDE5 had no effect with 8Br-cAMP.

These data lend support to the concept that cGMP may be a more potent signaling protein involved in the phosphorylation of
VASP in VSMCs. They also support the idea that cAMP is more tightly regulated in these cells and that elevation in cAMP inhibits the phosphorylation of VASP when it occurs simultaneously with cGMP which may be important physiologically for cell function. We can also conclude that the increases in cAMP in response to BAY are secondary to the increase with cGMP. A schematic representing this hypothesis is shown in Figure 10. The physiological and potentially pathophysiological role of this feedback and inherent mechanism(s) still needs to be explored in more detail. Overall, it appears that PDEs differentially regulate BAY-induced increases in VASP phosphorylation in VSMCs; however, the precise mechanisms of VASP phosphorylation by BAY remain to be further elucidated. 


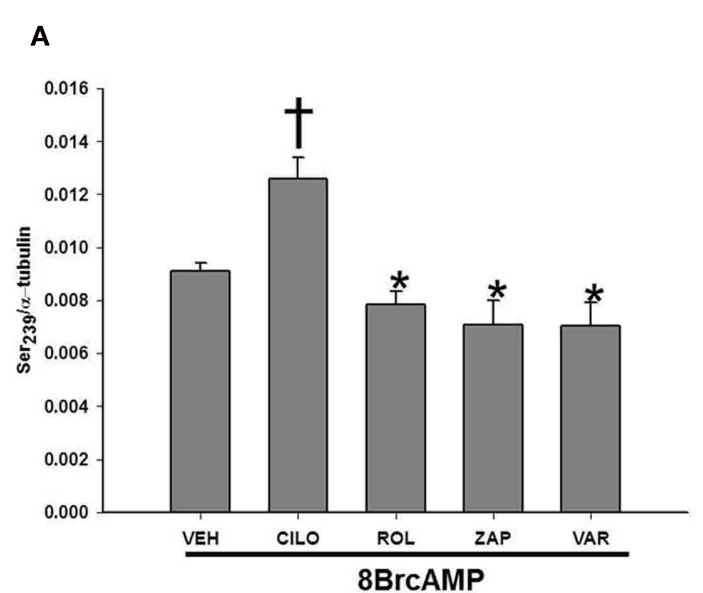

FIGURE 9 | (A) Effect of inhibitors of PDEs on 8Br-cAMP-induced VASPSer ${ }_{239}$ phosphorylation. VSMCs treated with $8 \mathrm{Br}-\mathrm{CAMP}(10 \mu \mathrm{M})$ in the absence or presence of cilostazol (CILO, $10 \mu \mathrm{M})$, rolipram $(R O L, 10 \mu \mathrm{M})$, zaprinast (ZAP, $10 \mu \mathrm{M})$, or vardenafil (VAR, $50 \mathrm{nM}),(n=3)$. Values are the means $\pm \mathrm{SE}$. ${ }^{*}$ Different from vehicle control $(P<0.05){ }^{\dagger}$ different from all other values

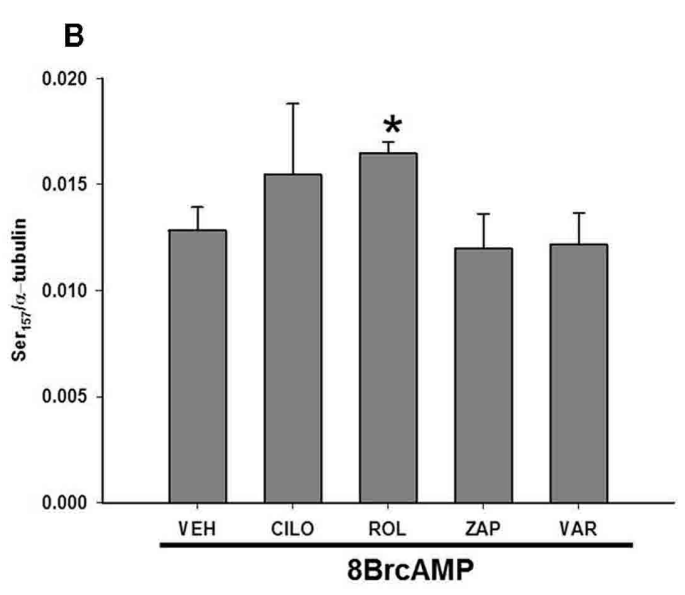

$(P<0.05)$. (B) Effect of inhibitors of PDEs on 8Br-cAMP-induced VASPSer ${ }_{157}$ phosphorylation. VSMCs treated with 8Br-CAMP $(10 \mu \mathrm{M})$ in the absence or presence of cilostazol (CILO, $10 \mu \mathrm{M})$, rolipram (ROL, $10 \mu \mathrm{M})$, zaprinast (ZAP, $10 \mu \mathrm{M})$, or vardenafil (VAR, $50 \mathrm{nM}),(n=3)$. Values are the means $\pm \mathrm{SE}$. *Different from vehicle control $(P<0.05)$.

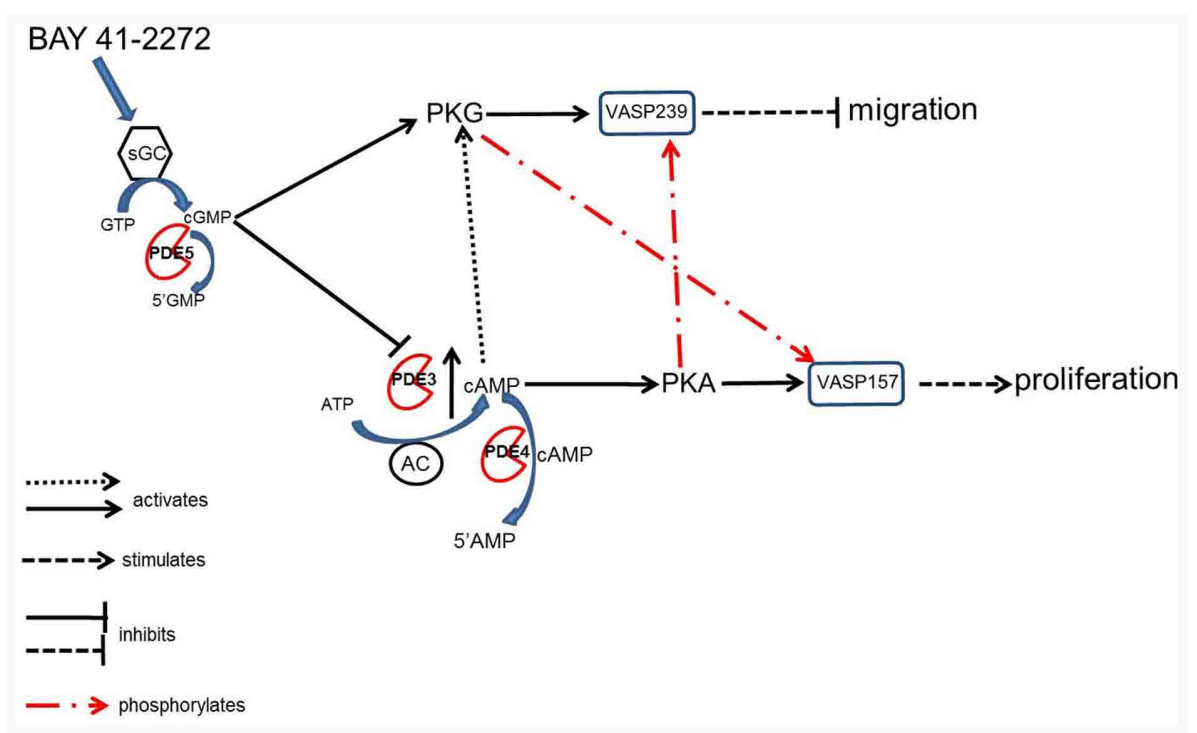

FIGURE 10 |According to these data in primary VSMCs we propose that BAY stimulates SGC and promotes synthesis of cGMP which directly activates PKG and phosphorylates VASP pSer $_{239}$ thus inhibiting cell migration (Chen et al., 2004). Cyclic GMP can also inhibit PDE3, thereby inhibiting degradation of CAMP and increasing the duration of its signal. An increase in CAMP can lead to stimulation of PKA and phosphorylation of VASP pSer ${ }_{157}$, resulting in proliferation of VSMCs (Chen et al., 2004). Our data indicate that an increase in cAMP in the presence of an increase in CGMP leads to negative regulation of VASP phosphorylation. Additionally, cyclic AMP can also stimulate PKG directly and activate its signaling pathway (Cornwell et al., 1994). These data also argue for crosstalk among the kinases where PKA can phosphorylate $\mathrm{pSer}_{239}$ and PKG pSer ${ }_{157}$. Lastly, PDE4 can regulate the increases in cAMP and therefore regulate phosphorylation of VASP.
Several limitations of this study are worth discussion. We have recently analyzed the concentration- and time-dependent effects of BAY in rat A7R5 VSMCs (Mendelev et al., 2009) and rat primary VSMCs (Joshi et al., 2011). These findings show growth-retarding effects of BAY at $10 \mu \mathrm{M}$. In logical continuation, in the current study all experiments were done at $10 \mu \mathrm{M}$ BAY. A potential limitation of this work could be that BAY exerts physiologic effects at lower concentrations, supported by data (see Figure 1). Moreover, feedback mechanisms involving kinases and PDEs can occur at lower cyclic nucleotide concentrations. Nonetheless, the potent in vitro effects presented here along with in vivo results observed recently (Joshi et al., 2011) suggest bioactivity of BAY at $10 \mu \mathrm{M}$, thus providing a pharmacologic target capable of reducing VSMC growth along with a potential biologic mechanism. It should be 
noted that $10 \mu \mathrm{M}$ BAY failed to exert noticeable toxicity in earlier studies (Mendelev et al., 2009; Joshi et al., 2011). The PDE inhibitors cilostazol, rolipram, vardenafil, and zaprinast are all selective to the PDE at the concentrations used. Cilostazol is a PDE3 inhibitor currently used in the treatment of intermittent claudication (Liu et al., 2001). Rolipram inhibits all isoforms of PDE4 and is highly selective (Schwabe et al., 1976; Lugnier et al., 1986; Komas et al., 1989). VAR and ZAP are both selective for PDE5; however both can inhibit PDE6 at concentrations higher than the $\mathrm{IC}_{50}$ (Lugnier, 2006). VAR is more potent than ZAP for PDE5 and as far as PDE6 being present in VSMC the role has yet to be investigated. The limitations of the use of a pharmacological inhibitor are that they can have effects on other pathways and PDEs are widely distributed throughout the cell having effects on multiple pathways. Additionally the $\mathrm{IC}_{50}$ can vary according to cell type and it can inhibit other PDEs as well.

\section{CONCLUSION}

In conclusion, cGMP signaling is considered antiproliferative and serves to protect the vasculature; however, the influence of selective pharmacologic modulation of sGC on VSMC growth and vessel

\section{REFERENCES}

Abel, K., Mieskes, G., and Walter, U. (1995). Dephosphorylation of the focal adhesion protein VASP in vitro and in intact human platelets. FEBS Lett. 370, 184-188.

Aizawa, T., Wei, H., Miano, J. M., Abe, J., Berk, B. C., and Yan, C. (2003). Role of phosphodiesterase 3 in NO/cGMP-mediated antiinflammatory effects in vascular smooth muscle cells. Circ. Res. 93, 406-413.

Baillie, G. S. (2009). Compartmentalized signalling: spatial regulation of cAMP by the action of compartmentalized phosphodiesterases. FEBS J. 276, 1790-1799.

Ballard, S. A., Gingell, C. J., Tang, K., Turner, L. A., Price, M. E., and Naylor, A. M. (1998). Effects of sildenafil on the relaxation of human corpus cavernosum tissue in vitro and on the activities of cyclic nucleotide phosphodiesterase isozymes. J. Urol. 159, 2164-2171.

Bawankule, D. U., Sathishkumar, K., Sardar, K. K., Chanda, D., Krishna, A. V., Prakash, V. R., and Mishra, S. K. (2005). BAY 41-2272 [5-cyclo propyl-2-[1-(2-fluoro-benzyl)-1Hpyrazolo[3,4-b]pyridine-3-yl]pyri midin-4-ylamine]-induced dilation in ovine pulmonary artery: role of sodium pump. J. Pharmacol. Exp. Ther. 314, 207-213.

Beavo, J. A., and Brunton, L. L. (2002). Cyclic nucleotide research - still

remodeling remain unclear. Increases in cGMP exert physiologic and pathophysiologic effects through multiple signaling pathways including direct kinase activation, indirect crosstalk with cAMP, or activation/inhibition of PDEs. In this study we demonstrate that pharmacologic stimulation of sGC via BAY exerts its effects via involvement of all three processes. These findings provide insight into the precise mechanisms of action of BAY in VSM and show that BAY operates through both cGMP and cAMP in these cells, thus increasing our understanding of the potential role of VASP and the sGC agonist BAY in cardiovascular disease.

\section{ACKNOWLEDGMENTS}

We would like to acknowledge Jonathan C. Fox and Patti Shaver for assistance with isolation and culture of rat primary vascular smooth muscle cells. This project was supported by Award Number R01HL081720 from the National Institutes of Health National Heart, Lung, and Blood Institute (NHLBI), by ARRA Award Number R01HL081720-03S2, and by Post-doctoral Research Supplement Award Number R01HL081720-05S1 from the NHLBI. This content is solely the responsibility of the authors and does not necessarily represent the official views of the NHLBI or the NIH.

orally active type 5 cyclic GMPspecific phosphodiesterase inhibitor for the treatment of penile erectile dysfunction. Int. J. Impot. Res. 8, 47-52.

Bos, J. L. (2003). Epac: a new cAMP target and new avenues in cAMP research. Nat. Rev. Mol. Cell Biol. 4, 733-738.

Butt, E., Abel, K., Krieger, M., Palm, D., Hoppe, V., Hoppe, J., and Walter, U. (1994). cAMP- and cGMPdependent protein kinase phosphorylation sites of the focal adhesion vasodilator-stimulated phosphoprotein (VASP) in vitro and in intact human platelets. J. Biol. Chem. 269, 14509-14517.

Cai, H., and Harrison, D. G. (2000) Endothelial dysfunction in cardiovascular diseases: the role of oxidant stress. Circ. Res. 87, 840-844.

Challah, M., Nadaud, S., Philippe, M., Battle, T., Soubrier, F., Corman, B., and Michel, J. B. (1997). Circulating and cellular markers of endothelial dysfunction with aging in rats. Am. J. Physiol. 273, H1941-H1948.

Chen, H., Kovar, J., Sissons, S., Cox, K., Matter, W., Chadwell, F., Luan, P., Vlahos, C. J., Schutz-Geschwender, A., and Olive, D. M. (2005). A cellbased immunocytochemical assay for monitoring kinase signaling pathways and drug efficacy. Anal. Biochem. 338, 136-142.

Chen, L., Daum, G., Chitaley, K., Coats, S. A., Bowen-Pope, D. F., Eigenthaler, M., Thumati, N. R., Walter, U., and
Clowes, A. W. (2004). Vasodilatorstimulated phosphoprotein regulates proliferation and growth inhibition by nitric oxide in vascular smooth muscle cells. Arterioscler. Thromb. Vasc. Biol. 24, 1403-1408.

Chitaley, K., Chen, L., Galler, A., Walter, U., Daum, G., and Clowes, A W. (2004). Vasodilator-stimulated phosphoprotein is a substrate for protein kinase C. FEBS Lett. 556, 211-215.

Cornwell, T. L., Arnold, E., Boerth, N. J., and Lincoln, T. M. (1994) Inhibition of smooth muscle cell growth by nitric oxide and activation of cAMP-dependent protein kinase by cGMP. Am. J. Physiol. 267, C1405-C1413.

Craven, K. B., and Zagotta, W. N. (2006). CNG and HCN channels: two peas, one pod. Annu. Rev. Physiol. 68, 375-401.

Degerman, E., Belfrage, P., and Manganiello, V. C. (1997). Structure, localization, and regulation of cGMP-inhibited phosphodiesterase (PDE3). J. Biol. Chem. 272, 6823-6826.

Deruelle, P., Balasubramaniam, V., Kunig, A. M., Seedorf, G. J., Markham, N. E., and Abman, S. H. (2006). BAY 41-2272, a direct activator of soluble guanylate cyclase, reduces right ventricular hypertrophy and prevents pulmonary vascular remodeling during chronic hypoxia in neonatal rats. Biol. Neonate 90, 135-144. 
Douglas, J. S. Jr., Holmes, D. R. Jr., Kereiakes, D. J., Grines, C. L., Block, E., Ghazzal, Z. M., Morris, D. C., Liberman, H., Parker, K., Jurkovitz, C., Murrah, N., Foster, J., Hyde, P., Mancini, G. B., and Weintraub, W. S. (2005). Coronary stent restenosis in patients treated with cilostazol. Circulation 112, 2826-2832.

Durante, W., Schini, V. B., Catovsky, S., Kroll, M. H., Vanhoutte, P. M., and Schafer, A. I. (1993). Plasmin potentiates induction of nitric oxide synthesis by interleukin-1 beta in vascular smooth muscle cells. Am. J. Physiol. 264, H617-H624.

Feil, R., Feil, S., and Hofmann, F. (2005). A heretical view on the role of $\mathrm{NO}$ and cGMP in vascular proliferative diseases. Trends. Mol. Med. 11, 71-75.

Freedman, J. E., Ting, B., Hankin, B., Loscalzo, J., Keaney, J. F. Jr., and Vita, J. A. (1998). Impaired platelet production of nitric oxide predicts presence of acute coronary syndromes. Circulation 98, 1481-1486.

Garg, U. C., and Hassid, A. (1989). Nitric oxide-generating vasodilators and 8-bromo-cyclic guanosine monophosphate inhibit mitogenesis and proliferation of cultured rat vascular smooth muscle cells. J. Clin. Invest. 83, 1774-1777.

Garthwaite, J., Southam, E., Boulton, C. L., Nielsen, E. B., Schmidt, K., and Mayer, B. (1995). Potent and selective inhibition of nitric oxide-sensitive guanylyl cyclase by $\quad 1 \mathrm{H}-[1,2,4]$ oxadiazolo $[4,3$ a] quinoxalin-1-one.

Mol. Pharmacol. 48, 184-188.

Haffner, C., Jarchau, T., Reinhard, M., Hoppe, J., Lohmann, S. M., and Walter, U. (1995). Molecular cloning, structural analysis and functional expression of the proline-rich focal adhesion and microfilament-associated protein VASP. EMBO J. 14, 19-27.

Hemnes, A. R., and Champion, H. C. (2006). Sildenafil, a PDE5 inhibitor, in the treatment of pulmonary hypertension. Expert Rev. Cardiovasc. Ther. 4, 293-300.

Ignarro, L. J., Harbison, R. G., Wood, K. S., and Kadowitz, P. J. (1986). Activation of purified soluble guanylate cyclase by endothelium-derived relaxing factor from intrapulmonary artery and vein: stimulation by acetylcholine, bradykinin and arachidonic acid. J. Pharmacol. Exp. Ther. 237, 893-900.

Indolfi, C., Avvedimento, E. V., Di Lorenzo, E., Esposito, G., Rapacciuolo, A., Giuliano, P., Grieco, D., Cavuto, L., Stingone, A. M., Ciullo,
I., Condorelli, G., and Chiariello, M. (1997). Activation of cAMP-PKA signaling in vivo inhibits smooth muscle cell proliferation induced by vascular injury. Nat. Med. 3, 775-779.

Joshi, C. N., Martin, D. N., Fox, J. C., Mendelev, N. N., Brown, T. A., and Tulis, D. A. (2011). The soluble guanylate cyclase stimulator BAY 412272 inhibits vascular smooth muscle growth through the PKA and PKG pathways. J. Pharmacol. Exp. Ther. 339, 394-402.

Kass, D. A., Champion, H. C., and Beavo, J. A. (2007a). Phosphodiesterase type 5: expanding roles in cardiovascular regulation. Circ. Res. 101, 1084-1095.

Kass, D. A., Takimoto, E., Nagayama, T., and Champion, H. C. (2007b). Phosphodiesterase regulation of nitric oxide signaling. Cardiovasc. Res. 75, 303-314.

Kaupp, U. B., and Seifert, R. (2001). Molecular diversity of pacemaker ion channels. Annu. Rev. Physiol. 63, 235-257.

Kaupp, U. B., and Seifert, R. (2002). Cyclic nucleotide-gated ion channels. Physiol. Rev. 82, 769-824.

Kawashima, S., Yamashita, T., Ozaki, M., Ohashi, Y., Azumi, H., Inoue, N., Hirata, K., Hayashi, Y., Itoh, H., and Yokoyama, M. (2001). Endothelial NO synthase overexpression inhibits lesion formation in mouse model of vascular remodeling. Arterioscler. Thromb. Vasc. Biol. 21, 201-207.

Keswani, A. N., Peyton, K. J., Durante, W., Schafer, A. I., and Tulis, D. A. (2009). The cyclic GMP modulators YC-1 and zaprinast reduce vessel remodeling through antiproliferative and proapoptotic effects. J. Cardiovasc. Pharmacol. Ther. 14, 116-124.

Ko, F. N., Wu, C. C., Kuo, S. C., Lee, F. Y., and Teng, C. M. (1994). YC-1, a novel activator of platelet guanylate cyclase. Blood 84, 4226-4233.

Komas, N., Lugnier, C., Le Bec, A., Serradeil-Le Gal, C., Barthelemy, G., and Stoclet, J. C. (1989). Differential sensitivity to cardiotonic drugs of cyclic AMP phosphodiesterases isolated from canine ventricular and sinoatrial-enriched tissues. J. Cardiovasc. Pharmacol. 14, 213-220.

Liu, X. M., Peyton, K. J., Mendelev, N. N., Wang, H., Tulis, D. A., and Durante, W. (2009). YC-1 stimulates the expression of gaseous monoxide-generating enzymes in vascular smooth muscle cells. Mol. Pharmacol. 75, 208-217.

Liu, Y., Shakur, Y., Yoshitake, M., and Kambayashi Ji, J. (2001). Cilostazol (pletal): a dual inhibitor of cyclic nucleotide phosphodiesterase type 3 and adenosine uptake. Cardiovasc. Drug Rev. 19, 369-386.

Loscalzo, J. (2001). Nitric oxide insufficiency, platelet activation, and arterial thrombosis. Circ. Res. 88, 756-762.

Lucas, K. A., Pitari, G. M., Kazerounian, S., Ruiz-Stewart, I., Park, J., Schulz, S., Chepenik, K. P., and Waldman, S. A. (2000). Guanylyl cyclases and signaling by cyclic GMP. Pharmacol. Rev. 52, 375-414.

Lugnier, C. (2006). Cyclic nucleotide phosphodiesterase (PDE) superfamily: a new target for the development of specific therapeutic agents. Pharmacol. Ther. 109, 366-398.

Lugnier, C., Schoeffter, P., Le Bec, A., Strouthou, E., and Stoclet, J. C. (1986). Selective inhibition of cyclic nucleotide phosphodiesterases of human, bovine and rat aorta. Biochem. Pharmacol. 35, 1743-1751.

Maurice, D. H., and Haslam, R. J. (1990). Molecular basis of the synergistic inhibition of platelet function by nitrovasodilators and activators of adenylate cyclase: inhibition of cyclic AMP breakdown by cyclic GMP. Mol. Pharmacol. 37, 671-681.

Mendelev, N. N., Williams, V. S., and Tulis, D. A. (2009). Antigrowth properties of BAY 41-2272 in vascular smooth muscle cells. J. Cardiovasc. Pharmacol. 53, 121-131.

Morbidelli, L., Pyriochou, A., Filippi, S., Vasileiadis, I., Roussos, C., Zhou, Z., Loutrari, H., Waltenberger, J., Stossel, A., Giannis, A., Ziche, M., and Papapetropoulos, A. (2010). The soluble guanylyl cyclase inhibitor NS2028 reduces vascular endothelial growth factor-induced angiogenesis and permeability. Am. J. Physiol. Regul. Integr. Comp. Physiol. 298, R824-832.

Mullershausen, F., Russwurm, M. Friebe, A., and Koesling, D. (2004). Inhibition of phosphodiesterase type 5 by the activator of nitric oxide-sensitive guanylyl cyclase BAY 41-2272. Circulation 109, 1711-1713.

Munzel, T., Daiber, A., and Mulsch, A. (2005). Explaining the phenomenon of nitrate tolerance. Circ. Res. 97, 618-628.

Nausch, L. W., Ledoux, J., Bonev, A. D., Nelson, M. T., and Dostmann, W. R. (2008). Differential patterning of cGMP in vascular smooth muscle cells revealed by single GFPlinked biosensors. Proc. Natl. Acad. Sci. U.S.A. 105, 365-370.

Ozaki, M., Kawashima, S., Yamashita, T., Hirase, T., Namiki, M., Inoue,
N., Hirata, K., Yasui, H., Sakurai, H., Yoshida, Y., Masada, M., and Yokoyama, M. (2002). Overexpression of endothelial nitric oxide synthase accelerates atherosclerotic lesion formation in apoE-deficient mice. J. Clin. Invest. 110, 331-340.

Palmer, D., and Maurice, D. H. (2000). Dual expression and differential regulation of phosphodiesterase 3A and phosphodiesterase $3 \mathrm{~B}$ in human vascular smooth muscle: implications for phosphodiesterase 3 inhibition in human cardiovascular tissues. Mol. Pharmacol. 58, 247-252.

Piggott, L. A., Hassell, K. A., Berkova, Z., Morris, A. P., Silberbach, M., and Rich, T. C. (2006). Natriuretic peptides and nitric oxide stimulate cGMP synthesis in different cellular compartments. J. Gen. Physiol. 128, 3-14.

Polson, J. B., and Strada, S. J. (1996). Cyclic nucleotide phosphodiesterases and vascular smooth muscle. Annu. Rev. Pharmacol. Toxicol. 36, 403-427.

Raymond, D. R., Wilson, L. S., Carter, R. L., and Maurice, D. H. (2007). Numerous distinct PKA-, or EPACbased, signalling complexes allow selective phosphodiesterase 3 and phosphodiesterase 4 coordination of cell adhesion. Cell. Signal. 19, 2507-2518.

Rehmann, H., Wittinghofer, A., and Bos, J. L. (2007). Capturing cyclic nucleotides in action: snapshots from crystallographic studies. Nat. Rev. Mol. Cell Biol. 8, 63-73.

Rindone, J. P., and Sloane, E. P. (1992). Cyanide toxicity from sodium nitroprusside: risks and management. Ann. Pharmacother. 26, 515-519.

Roger, S., Badier-Commander, C., Paysant, J., Cordi, A., Verbeuren, T. J., and Feletou, M. (2010). The anti-aggregating effect of BAY 412272 , a stimulator of soluble guanylyl cyclase, requires the presence of nitric oxide. Br. J. Pharmacol. 161, 1044-1058.

Rose, R. J., Liu, H., Palmer, D., and Maurice, D. H. (1997). Cyclic AMPmediated regulation of vascular smooth muscle cell cyclic AMP phosphodiesterase activity. $\mathrm{Br} . \mathrm{J}$. Pharmacol. 122, 233-240.

Rudic, R. D., Shesely, E. G., Maeda, N., Smithies, O., Segal, S. S., and Sessa, W. C. (1998). Direct evidence for the importance of endothelium-derived nitric oxide in vascular remodeling. J. Clin. Invest. 101, 731-736.

Rybalkin, S. D., Yan, C., Bornfeldt, K. E., and Beavo, J. A. (2003). Cyclic GMP phosphodiesterases and regulation 
of smooth muscle function. Circ. Res. 93, 280-291.

Sarkar, R., Meinberg, E. G., Stanley, J. C., Gordon, D., and Webb, R. C. (1996). Nitric oxide reversibly inhibits the migration of cultured vascular smooth muscle cells. Circ. Res. 78, 225-230.

Sasaki, N., Yamashita, T., Takaya, T., Shinohara, M., Shiraki, R., Takeda, M., Emoto, N., Fukatsu, A., Hayashi, T., Ikemoto, K., Nomura, T., Yokoyama, M., Hirata, K., and Kawashima, S. (2008). Augmentation of vascular remodeling by uncoupled endothelial nitric oxide synthase in a mouse model of diabetes mellitus. Arterioscler. Thromb. Vasc. Biol. 28, 1068-1076.

Schwabe, U., Miyake, M., Ohga, Y., and Daly, J. W. (1976). 4-(3Cyclopentyloxy-4-methoxyphenyl)2-pyrrolidone (ZK 62711): a potent inhibitor of adenosine cyclic $3^{\prime}, 5^{\prime}$-monophosphate phosphodiesterases in homogenates and tissue slices from rat brain. Mol. Pharmacol. 12, 900-910.

Seino, S., and Shibasaki, T. (2005). PKAdependent and PKA-independent pathways for cAMP-regulated exocytosis. Physiol. Rev. 85, 1303-1342.

Stasch, J. P., Becker, E. M., AlonsoAlija, C., Apeler, H., Dembowsky, K., Feurer, A., Gerzer, R., Minuth, T., Perzborn, E., Pleiss, U., Schroder, H., Schroeder, W., Stahl, E., Steinke, W., Straub, A., and Schramm, M. (2001). NO-independent regulatory site on soluble guanylate cyclase. Nature 410, 212-215.

Stasch, J. P., Schmidt, P., Alonso-Alija, C., Apeler, H., Dembowsky, K., Haerter, M., Heil, M., Minuth, T.,
Perzborn, E., Pleiss, U., Schramm, M., Schroeder, W., Schroder, H., Stahl, E., Steinke, W., and Wunder, F. (2002). NO- and haemindependent activation of soluble guanylyl cyclase: molecular basis and cardiovascular implications of a new pharmacological principle. $\mathrm{Br}$. J. Pharmacol. 136, 773-783.

Straub, A., Stasch, J. P., Alonso-Alija, C., Benet-Buchholz, J., Ducke, B., Feurer, A., and Furstner, C. (2001). NO-independent stimulators of soluble guanylate cyclase. Bioorg. Med. Chem. Lett. 11, 781-784.

Sydow, K., Daiber, A., Oelze, M., Chen, Z., August, M., Wendt, M., Ullrich, V., Mulsch, A., Schulz, E., Keaney, J. F. Jr., Stamler, J. S., and Munzel, T. (2004). Central role of mitochondrial aldehyde dehydrogenase and reactive oxygen species in nitroglycerin tolerance and cross-tolerance. J. Clin. Invest. 113, 482-489.

Teixeira, C. E., Priviero, F. B., and Webb, R. C. (2006). Molecular mechanisms underlying rat mesenteric artery vasorelaxation induced by the nitric oxide-independent soluble guanylyl cyclase stimulators BAY 41-2272 [5-cyclopropyl2-[1-(2-fluorobenzyl)-1Hpyrazolo[3,4-b]pyridin-3-yl]pyrimi din-4-ylamine $]$ and YC-1 [3-(5'hydroxymethyl-2'-furyl)-1-benzyl Indazole]. J. Pharmacol. Exp. Ther. 317, 258-266.

Thorsen, L. B., Eskildsen-Helmond, Y., Zibrandtsen, H., Stasch, J. P., Simonsen, U., and Laursen, B. E. (2010). BAY 41-2272 inhibits the development of chronic hypoxic pulmonary hypertension in rats. Eur. J. Pharmacol. 647, 147-154.
Tilley, D. G., and Maurice, D. H (2002). Vascular smooth muscle cell phosphodiesterase (PDE) 3 and PDE4 activities and levels are regulated by cyclic AMP in vivo. Mol. Pharmacol. 62, 497-506.

Tulis, D. A. (2008). Novel therapies for cyclic GMP control of vascular smooth muscle growth. Am. J. Ther. $15,551-564$.

Vaandrager, A. B., and de Jonge, $\mathrm{H}$ R. (1996). Signalling by cGMPdependent protein kinases. Mol. Cell. Biochem. 157, 23-30.

Varenne, O., Pislaru, S., Gillijns, H. Van Pelt, N., Gerard, R. D., Zoldhelyi, P., Van De Werf, F., Collen, D., and Janssens, S. P. (1998). Local adenovirus-mediated transfer of human endothelial nitric oxide synthase reduces luminal narrowing after coronary angioplasty in pigs. Circulation 98 919-926.

Wilson, L. S., Elbatarny, H. S., Crawley, S. W., Bennett, B. M., and Maurice, D. H. (2008). Compartmentation and compartment-specific regulation of PDE5 by protein kinase $\mathrm{G}$ allows selective cGMP-mediated regulation of platelet functions. Proc. Natl. Acad. Sci. U.S.A. 105, 13650-13655

Yu, S. M., Hung, L. M., and Lin, C. C. (1997). cGMP-elevating agents suppress proliferation of vascular smooth muscle cells by inhibiting the activation of epidermal growth factor signaling pathway. Circulation 95, 1269-1277.

Zaccolo, M., and Movsesian, M. A. (2007). cAMP and cGMP signaling cross-talk: role of phosphodiesterases and implications for cardiac pathophysiology. Circ. Res. 100, 1569-1578.

Zaccolo, M., and Pozzan, T. (2002). Discrete microdomains with high concentration of cAMP in stimulated rat neonatal cardiac myocytes. Science 295, 1711-1715.

Zhao, H., Guan, Q., Smith, C. J. and Quilley, J. (2008). Increased phosphodiesterase $3 \mathrm{~A} / 4 \mathrm{~B}$ expression after angioplasty and the effect on VASP phosphorylation. Eur. J. Pharmacol. 590, 29-35.

Conflict of Interest Statement: The authors declare that the research was conducted in the absence of any commercial or financial relationships that could be construed as a potential conflict of interest.

Received: 05 December 2011; accepted: 18 January 2012; published online: 07 February 2012.

Citation: Adderley SP, Joshi CN, Martin DN and Tulis DA (2012) Phosphodiesterases regulate BAY 41-2272induced VASP phosphorylation in vascular smooth muscle cells. Front. Pharmacol. 3:10. doi: 10.3389/fphar.2012.00010 This article was submitted to Frontiers in Cardiovascular and Smooth Muscle Pharmacology, a specialty of Frontiers in Pharmacology.

Copyright (c) 2012 Adderley, Joshi, Martin and Tulis. This is an open-access article distributed under the terms of the Creative Commons Attribution Non Commercial License, which permits noncommercial use, distribution, and reproduction in other forums, provided the original authors and source are credited. 